References:

[1] Franklyn K, Lau CS, Navarra SV, Louthrenoo W, Lateef A, Hamijoyo L, Wahono CS, Chen SL, Jin O, Morton S, Hoi A, Huq M, Nikpour M, Morand EF; Asia-Pacific Lupus Collaboration. Ann Rheum Dis. 2016 Sep;75(9):1615-21.

Table 1 Baseline variables associated with LLDAS achievement based on multivariable Cox models

\begin{tabular}{|c|c|c|c|c|c|c|}
\hline \multirow[t]{2}{*}{ Characteristics } & \multicolumn{2}{|c|}{ Model 1} & \multicolumn{2}{|c|}{ Model 2} & \multicolumn{2}{|l|}{ Model 3} \\
\hline & HR $(95 \% \mathrm{Cl})$ & $p$ value & $\mathrm{HR}(95 \% \mathrm{Cl})$ & $p$ value & HR (95\% Cl) & $\begin{array}{c}p \\
\text { value }\end{array}$ \\
\hline $\begin{array}{l}\text { Age at disease onset, } \\
\text { years }\end{array}$ & $\begin{array}{c}1.010 \\
(1.003-1.016)\end{array}$ & 0.005 & $\begin{array}{c}1.009 \\
(1.002-1.016)\end{array}$ & 0.010 & $\begin{array}{c}1.010 \\
(1.003-1.017)\end{array}$ & 0.004 \\
\hline Treatment-naïve & $\begin{array}{c}1.346 \\
(1.105-1.641)\end{array}$ & 0.003 & $\begin{array}{c}1.425 \\
(1.161-1.749)\end{array}$ & 0.001 & $\begin{array}{c}1.484 \\
(1.204-1.830)\end{array}$ & $<0.001$ \\
\hline Nephritis & $\begin{array}{c}0.776 \\
(0.641-0.939)\end{array}$ & 0.009 & $\begin{array}{c}1.066 \\
(0.820-1.385)\end{array}$ & 0.634 & $\begin{array}{c}0.925 \\
(0.737-1.160)\end{array}$ & 0.498 \\
\hline SLEDAI & & & $\begin{array}{c}0.968 \\
(0.950-0.987)\end{array}$ & 0.001 & & \\
\hline PGA & & & & & $\begin{array}{c}0.685 \\
(0.551-0.853)\end{array}$ & 0.001 \\
\hline $\begin{array}{l}\text { Daily prednisone (or } \\
\text { equivalent) dose, } \\
\mathrm{mg} / \mathrm{d}\end{array}$ & & & $\begin{array}{c}1.003 \\
(0.998-1.007)\end{array}$ & 0.266 & $\begin{array}{c}1.005 \\
(0.999-1.010)\end{array}$ & 0.093 \\
\hline $\mathrm{HCQ}$ & $\begin{array}{c}1.638 \\
(1.263-2.123)\end{array}$ & $<0.001$ & $\begin{array}{c}1.713 \\
(1.318-2.225)\end{array}$ & $<0.001$ & $\begin{array}{c}1.664 \\
(1.284-2.157)\end{array}$ & $<0.001$ \\
\hline
\end{tabular}

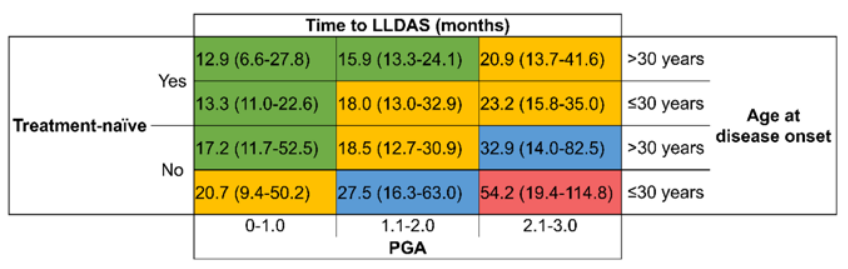

Figure 1 Matrix model for time to LLDAS.

Disclosure of Interests: None declared

DOI: 10.1136/annrheumdis-2020-eular.3149

\section{THU0248 GLOMERULAR AND TUBULOINTERSTITIAL LESIONS IN PER-PROTOCOL REPEAT BUT NOT BASELINE KIDNEY BIOPSY PORTEND RELAPSE AND LONG-TERM RENAL FUNCTION IMPAIRMENT, RESPECTIVELY, IN INCIDENT CASES OF PROLIFERATIVE LUPUS NEPHRITIS}

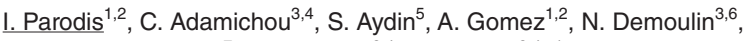
J. Weinmann-Menke ${ }^{7}$, F. Houssiau ${ }^{3,4}$, F. Tamirou ${ }^{3,4}$. ${ }^{1}$ Karolinska Institutet, Department of Medicine Solna, Stockholm, Sweden; ${ }^{2}$ Karolinska University Hospital, Rheumatology, Stockholm, Sweden; ${ }^{3}$ Université Catholique de Louvain, Institut de Recherche Expérimentale et Clinique, Brussels, Belgium; ${ }^{4}$ Cliniques Universitaires Saint-Luc, Rheumatology Department, Brussels, Belgium; ${ }^{5}$ Cliniques Universitaires Saint-Luc, Pathology Department, Brussels, Belgium; ${ }^{6}$ Cliniques Universitaires Saint-Luc, Division of Nephrology, Brussels, Belgium; ${ }^{7}$ University Medical Centre of the Johannes Gutenberg University of Mainz, Department of Nephrology, Rheumatology and Clinical Immunology, Mainz, Germany

Background: In patients with lupus nephritis (LN), clinical response to treatment and renal histopathology have been shown to be discordant. No clinical or laboratory markers have to date been shown to reliably portend renal prognosis, in particular renal function impairment.

Objectives: To investigate whether per-protocol repeat renal biopsies are predictive of $L N$ relapses and long-term impairment of renal function.

Methods: Forty-two patients with an incident biopsy-proven active proliferative (class III/IV $\pm \mathrm{V}$ ) $L N$ from the $L N$ database of the Universite catholique de Louvain were included in the present retrospective study. Per-protocol repeat kidney biopsies were performed in all patients after a median time of 24.3 (IQR: 21.3-26.2) months. The $\mathrm{NIH}$ activity index (AI) and chronicity index (Cl) scores were assessed in both baseline and repeat biopsies. We defined acute glomerular lesions as cellular proliferation, fibrinoid necrosis or karyorrhexis, cellular crescents, hyaline thrombi or wire loops, and leucocyte infiltration, and chronic glomerular lesions as glomerular sclerosis and fibrous crescents, in alignment with the NIH activity and chronicity indices. Similarly, we defined acute tubulointerstitial lesions as mononuclear cell infiltration and chronic tubulointerstitial lesions as interstitial fibrosis and tubular atrophy.

Results: Despite a moderate correlation between urinary protein/creatinine $(\mathrm{U}-\mathrm{P} / \mathrm{C})$ ratios and $\mathrm{Al}$ scores at repeat biopsy $(\mathrm{r}=0.48$; $\mathrm{P}=0.001)$, ten patients $(23.8 \%)$ with $\mathrm{U}-\mathrm{P} / \mathrm{C}$ ratios $<1.0 \mathrm{~g} / \mathrm{g}$ still had a high degree of histological activity (Al score $>3$ ). High Al scores in repeat (but not baseline) kidney biopsies were associated with an increased probability and/or shorter time to renal relapse $(\mathrm{N}=11)$ following the repeat biopsy (HR: $1.2 ; 95 \% \mathrm{Cl}: 1.1-1.3 ; \mathrm{P}=0.007)$, independently of proteinuria levels. This association remained significant for the $\mathrm{NIH}$ activity index items within the glomerular but not the tubulointerstitial compartment of the kidney biopsies. High $\mathrm{NIH} \mathrm{Cl}$ scores in repeat (but not baseline) kidney biopsies were associated with a sustained increase in serum creatinine levels corresponding to $\geq 120 \%$ of the baseline value (HR: $1.8 ; 95 \% \mathrm{Cl}: 1.1-2.9$; $\mathrm{P}=0.016$ ) through a median follow-up time of 131.5 (IQR: 73.8-178.2) months, being the case also for acute and chronic tubulointerstitial lesions in repeat but not baseline kidney biopsies.

Conclusion: Our results highlight the usefulness of per-protocol repeat biopsies as an integral part of the treatment evaluation, also in patients who have shown adequate clinical response. Glomerular lesions consistent with active renal disease portend $\mathrm{LN}$ relapses, while tubulointerstitial lesions consistent with active disease and chronic damage portent long-term renal function impairment.

Disclosure of Interests: Ioannis Parodis: None declared, Christina Adamichou: None declared, Selda Aydin: None declared, Alvaro Gomez: None declared, Nathalie Demoulin: None declared, Julia Weinmann-Menke: None declared, Frederic Houssiau Grant/research support from: UCB, Consultant of: GSK, Farah Tamirou: None declared DOI: 10.1136/annrheumdis-2020-eular.5863

\section{THU0249 CLINICAL FEATURES AND RENAL PROGNOSIS IN LUPUS NEPHRITIS PATIENTS UNDERGOING A REPEATED BIOPSY: RESULTS OF 103 RE-BIOPSIES IN 438 PATIENTS}

M. Gatto ${ }^{1}$, F. Saccon ${ }^{1}$, F. Radice ${ }^{2}$, P. G. Vercelloni ${ }^{2}$, R. A. Sinico ${ }^{2}$, G. Frontini ${ }^{3}$, V. Binda ${ }^{3}$, P. Messa ${ }^{3}$, F. Alberici ${ }^{4}$, G. Moroni ${ }^{3}$, A. Doria ${ }^{1}$. ${ }^{1}$ University of Padova, Unit of Rheumatology - Department of Medicine, Padova, Italy; ${ }^{2}$ Università Milano Bicocca - ASST Monza - S Gerardo, Nefrologia, Monza, Italy; ${ }^{3}$ Fondazione IRCCS Ca Granda Ospedale Maggiore Policlinico, Nefrologia, Milano, Italy; ${ }^{4}$ ASST Santi Paolo e Carlo, Ospedale San Carlo Borromeo, Nefrologia, Milano, Italy

Background: Indications to repeat renal biopsy (RB) in lupus nephritis (LN) are not unanimously acknowledged.

Objectives: To evaluate the renal outcome of patients with $\mathrm{LN}$ undergoing a second RB.

Methods: We retrospectively analyzed prospectively collected data of patients with LN followed up in four Italian referral centres for systemic lupus eryhtematosus. Serological and clinical information were retrieved according to a shared database. RB were classified according to ISN/RPS 2003 classification; chronicity $(\mathrm{Cl})$ and activity indexes (AI) were defined according to Austin et al. The primary renal outcome was renal failure, defined as serum creatinine $(\mathrm{SCr})>1.0 \mathrm{mg} / \mathrm{dL}$ with eGFR $<60 \mathrm{ml} / \mathrm{min}$. Non-parametric tests were used for statistics. Patients repeating RB due to renal remission were excluded from the analysis.

Results: Four-hundred and thirty-eight patients were recruited. One-hundred and three patients repeated RB after $6.1 \pm 4.7$ (mean $\pm S D$ ) years from the first due to: protocol biopsy due to renal remission (Group 1, $n=8$ ); proteinuric flare (Group 2, $n=51$ ); worsened renal function (Group 3, $n=26$ ); partial renal response (Group $4 \mathrm{n}=18)$. Patients undergoing a second RB were younger $(\mathrm{p}<0.001)$, had lower serum $\mathrm{C} 3$ at $\mathrm{LN}$ diagnosis $(\mathrm{p}<0.001)$ and displayed more frequently class IV and higher Al at first RB ( $p=0.0038$ and $p=0.043$, respectively). At the end of follow-up, patients who repeated $R B$ had more frequently renal failure $(p=0.003)$. At the second RB, the histological class was unchanged in $55 \%$ of patients. $\mathrm{Cl}$ increased at second RB compared to the first $(3.6 \pm 2.4$ vs. $1.7 \pm 1.7 ; p<0.001)$ Overall, 26 out of 103 patients (25\%) developed renal failure: 0 from group 1, 10 from group 2, 14 from group 3, 2 from group $4(p<0.001)$. Uncontrolled hypertension at LN diagnosis, increased $\mathrm{SCr}$ and increased proteinuria at second RB predicted renal failure (Table)

Conclusion: Patients undergoing a repeated RB had more aggressive clinical and histological features already at first RB and developed renal failure more frequently. Among baseline features, uncontrolled hypertension had the strongest association with renal failure, thus suggesting that control of blood pressure since early stages is highly advisable.

References:

[1] Austin HA, et al. Predicting renal outcomes in severe lupus nephritis: contributions of clinical and histologic data. Kidney Int 1994;45:544-50. 